\title{
Research on Optimization of Intelligent Warehousing Business of State Grid Based on Genetic Algorithm
}

\author{
Xin Jin* \\ School of Information, Central University of Finance and Economics, Beijing, China. \\ * Corresponding author. Tel.: 8601062289127; email: jinxin@cufe.edu.cn \\ Manuscript submitted January 10, 2018; accepted March 8, 2018. \\ doi: $10.17706 /$ jcp.13.10.1164-1170
}

\begin{abstract}
The optimization of the warehousing business is very important for establishing the modernized material management system and optimizing the material distribution efficiency of the state grid. In order to improve the efficiency of warehouse operation, this paper proposes a sorting business optimization strategy based on GA algorithm. The results of the simulation experiments show that the picking time and distance are greatly reduced with the GA optimization algorithm compared with before optimization. The GA optimization algorithm improved the efficiency of the picking, proved the reliability of the optimization strategy this paper proposed. The optimization strategy of sorting business will also have positive reference for other warehousing business optimization.
\end{abstract}

Key words: GA algorithm, state grid, optimization of warehousing business, sorting business.

\section{Introduction}

State Grid Corporation of China (shortly as State Grid) attaches great importance to materials warehouse management, especially information construction of warehouse management. According to the state grid related provisions on warehousing management, State Grid will be based on the "virtual warehouse" as the information center, combine its own warehousing with suppliers, make the central repository, regional repository and turnover repository as the warehouse network. The entity repository can be established for central warehouse of the provincial branch company. The intelligent warehouse is one of the warehouse types advocated by the State Grid. It is managed by the most advanced technology such as computer, information and communication, to improve warehousing and distribution capacity. Warehousing business management and optimization is an important part of the State Grid to build lean and efficient material management system. The goods storage, sorting and other operations are associated with the flow efficiency of materials, especially the sorting business directly related to the later period of logistics distribution. Optimization of warehousing service and building the intelligent warehouse management system are very important to build modern material management system of State Grid [1], [2].

The main business of entity repository includes storage, shelf, sorting, counting. Sorting service is one of the important part in the whole logistics system. Sorting operation aims to be able to quickly and accurately set products the user ordered. Optimization sorting service can greatly reduce logistics cost and improve the efficiency of logistics. Current sorting strategy is completely sequential sorting operation strategy, that is, directly picks goods with randomly order group by faculty, according to random access to goods orders, in addition to considering picking trucks volume without any optimization. This strategy has great randomness. If a group happens to contain goods picking location, picking speed is fast, otherwise, it may 
cross multiple regions to pick, which result in inefficient picking. Of course, besides sorting strategy, there are other reasons that will lead to lower picking efficiency, such as the storage of goods is not rationalized to find goods easily, or the rate of shortage is too high, and the picking path is redundant [3].

Taking sorting process as an example in this paper, a warehousing business optimization strategy based on GA genetic algorithm is proposed. After algorithm optimization, sorting efficiency can be greatly improved. Genetic algorithm is applied in many industries. Its advantage is to use the probabilistic search technology to solve the multi-point search in the solution space, avoiding the local minimum value, increasing the flexibility of search and improving the computing speed of the system [4]-[6]. The optimization strategy for sorting business will also provide a strong reference for other businesses such as warehousing, up and down shelves, inventory and so on.

\section{Optimization Strategy of Warehouse Sorting Business Based on GA Algorithm}

\subsection{Business Scenario Designing and Optimization Modeling}

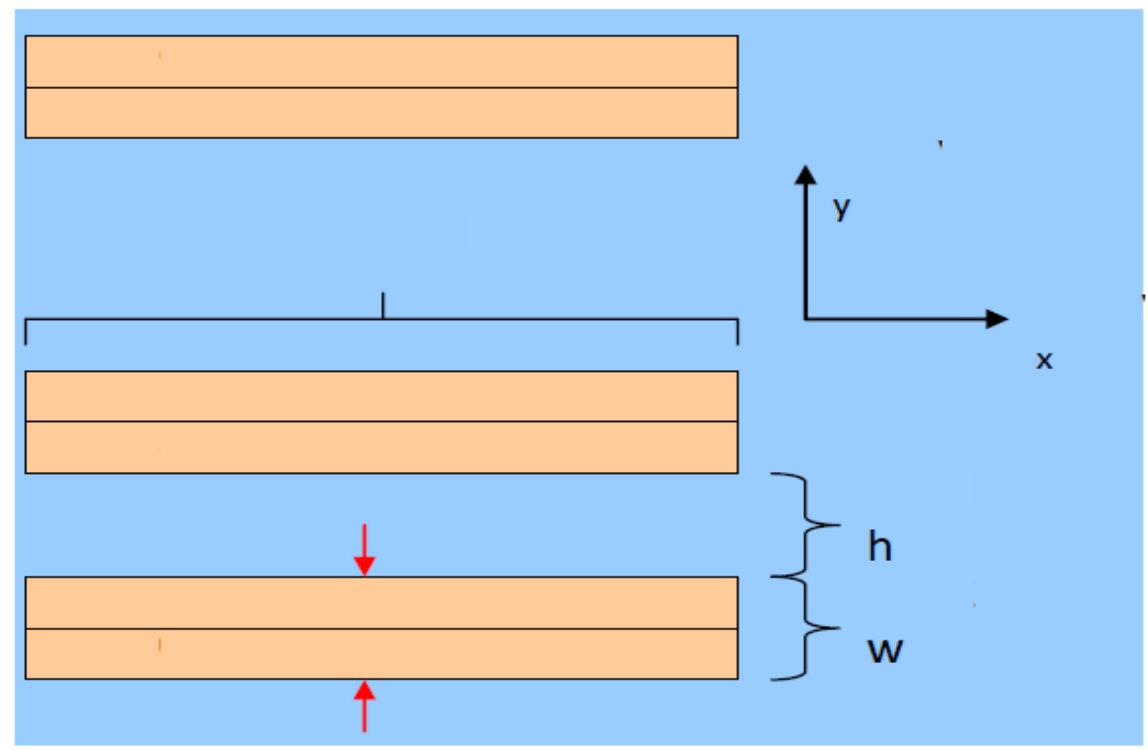

Fig. 1. Schematic diagram of shelf placement.

Supposing that in a warehouse, there are s shelves (the shelf number $t=0,1, \bullet \mathrm{s}-1$ ). Each two shelves is put together back to back in a set. There is a channel between the two sets of shelves, the channel width is $h$. Each shelf with length $b$ and width w, consists of $n^{*} m$ same size grid. Each grid is put different goods, the position of the goods at the shelf $y$ of the line $z$ and the column $x$ named as $(z, x, y), 0<z \leq n, 0<x \leq m$. The speed of the pickup is $V x$ in the horizontal direction and $V y$ in the longitudinal direction. Fig. 1 shows the schematic diagram of shelf placement.

Assuming that the picking time is same in the same column, the number of the goods can be described as $(x, y)$ in the calculation. Assuming that the calculation formula of the goods from the position of goods I to the time of goods $j$ is from the location of the goods $I$ to the distance of the goods $j$, and the calculation formula is as follows:

Assuming that, $t_{i j}$ is the picking time from position of the goods $i$, to the position of the goods $j, d_{i j}$ is the distance from i to $\mathrm{j}$. The formulas of $t_{i j}$ and $d_{i j}$ are following as:

$$
\underline{t_{i j}=x_{i j} / v_{X}+y_{i j} / v_{y} /}
$$


If goods $I$ and $j$ belong to adjacent shelves, the distance is following as:

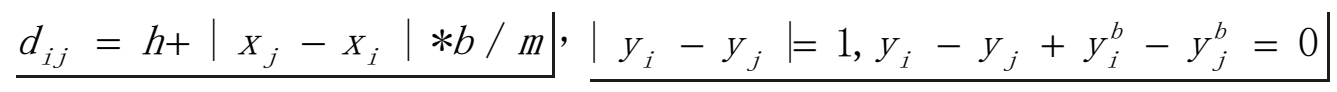

If goods $i$ and $j$ belong to the same shelf, the distance is following as:

$$
d_{i j}=\left|x_{j}-x_{i}\right| * b / m|, \quad| y_{i}-y_{j}|=0|
$$

In the rest of the situation, the distance is following as:

$$
d_{i j}=h\left|y_{i}^{a}-y_{j}^{a}\right|+2 w \| y_{i}^{a}-y_{j}^{a}\left|-y_{i}^{b}+y_{j}^{b}\right|+\min \left\{x_{i}+x_{j}, 2 m-x_{i}-x_{j}\right\}^{*} b / m
$$

where, $x_{i j}$ and $y_{i j}$ are the horizontal and longitudinal distance of the goods $i$ to the goods $j$ respectively, $y^{a}=\mathrm{y} / 2, \quad y^{b}=\mathrm{y} \% 2$.

The picking path optimization object is the minimum time and path to pick up all goods. Because the path and time are linearly positive, the combination can be described as follows:

$$
Z=\min \sum\left(\alpha t_{i j}+\beta d_{i j}\right)
$$

where $\alpha, \beta$ is the function correction factor.

\subsection{Optimization Solution Based on Genetic Algorithm}

Genetic algorithm (GA) is a meta heuristic inspired by the process of natural selection that belongs to the larger class of evolutionary algorithms (EA). Genetic algorithms are commonly used to generate high-quality solutions to optimization and search problems by relying on bio-inspired operators such as mutation, crossover and selection. In a genetic algorithm, a population of candidate solutions (called individuals) to an optimization problem is evolved toward better solutions. Each candidate solution has a set of properties which can be mutated and altered. The evolution usually starts from a population of randomly generated individuals, and is an iterative process, with the population in each iteration called a generation. In each generation, the fitness of every individual in the population is evaluated; the fitness is usually the value of the objective function in the optimization problem being solved. The more fit individuals are stochastically selected from the current population, and each individual's genome is modified (recombined and possibly randomly mutated) to form a new generation. The new generation of candidate solutions is then used in the next iteration of the algorithm. Commonly, the algorithm terminates when either a maximum number of generations has been produced, or a satisfactory fitness level has been reached for the population. A typical genetic algorithm requires a genetic representation of the solution domain and a fitness function to evaluate the solution domain. A standard representation of each candidate solution is as an array of bits. Arrays of other types and structures can be used in essentially the same way. The main property that makes these genetic representations convenient is that their parts are easily aligned due to their fixed size, which facilitates simple crossover operations. Once the genetic representation and the fitness function are defined, a GA proceeds to initialize a population of solutions and then to improve it through repetitive application of the mutation, crossover and selection operators. Genetic algorithm has the advantage of using probability search technology at the same time, the more search the solution space, the more avoiding the trapped in local minimum value and increasing the flexibility of the search to improve the computing speed of the system.

The algorithm operation of solving optimization targets mainly includes population representation, genetic operation and fitness calculation of genetic algorithm.

In solving the above optimization problems, the sequence of traversal goods is used to code. For example, the code 123456 indicates that the goods 1, 2, 3, 4, 5, 6 have been picked up one by one from the beginning of the serial number 1 , and finally returns the starting point 1 . Due to the initialization of the feasible 
solution group, crossover operation and mutation operation are implied solve the legitimacy of the constraint condition, then take the reciprocal of the objective function and fitness function is $f=1 / Z$, no penalty function.

\subsection{Operation of Genetic Algorithm}

Genetic operator includes selection, crossover and mutation.

1) Selection

Selection operation uses roulette betting method, and the selection strategy is adopted based on fitness ratio. The selection probability of each individual i is

$$
p_{i}=\frac{f_{i}}{\sum_{j=1}^{N} f_{j}}
$$

where, $\mathrm{f}_{i}=k / F_{\mathrm{i}}, K$ is the coefficient, $N$ is the number of individuals $F_{\mathrm{i}}$ is the fitness value of the individual $i$. The reciprocal of the fitness value should be evaluated before individual selection because the smaller of the fitness value is better.

2) Crossover

The crossover operation of the $k_{t h}$ chromosome $a_{k}$ and the $i_{t h}$ chromosome $a_{l}$ in position $j$ is as follows:

$$
\left.\begin{array}{l}
a_{k j}=a_{k j}(1-b)+a_{i j} b \\
a_{1 j}=a_{1 j}(1-b)+a_{k j} b
\end{array}\right\}
$$

where, $b$ is the random number between $[0,1]$.

3) Mutation

The mutation operation of the $j_{t h}$ gene $a_{i j}$ selected from the $I_{t h}$ individual is as follows:

$$
a_{i j}= \begin{cases}a i j+\left(a_{i j}-a_{\max }\right) * f(g) & r \geq 0.5 \\ a i j+\left(a_{\min }-a_{i j}\right) * f(g) & r<0.5\end{cases}
$$

where, $a_{\max }$ is the upper bound of gene $a_{i j}, a_{\min }$ is the lower bound of gene $a_{i j}$,

$f(g)=r_{2}(1-g / G \max ), r_{2}$ is a random number, $g$ is the current iteration number, $G_{\max }$ is the maximum number of times, $r$ is the random number between $[0,1]$.

The advantage of genetic algorithm is that in the use of probabilistic search technology, the multi-point search of the solution space increases the flexibility of the search and avoids the local minimum. In addition, the genetic algorithm has the characteristics of parallel computation, which can be improved by large-scale parallel computation.

\section{Simulation Experiment of Picking Business Optimization}

\subsection{Data Preparation}

Randomly generate 30 goods (numbered $\mathrm{I}=1, \ldots, 30)$, and the $i_{\text {th }}$ goods is $\left(x_{i}, y_{i}\right)$. The goods are divided into three groups, and the goods clerk needs to return three times to get all the goods. The clerk takes the goods in one group and returns the origin from the origin. Assuming that all the goods are picked, the volume is set to 1 , the volume of the cart is 10 . As a result, the clerk takes up to 10 items at a time to return to the original place $(0,0)$.

According to the above experimental hypothesis, the data table of the known data and the random generated data is listed below. 
Table 1. Constant Data

\begin{tabular}{|c|c|c|c|c|c|c|c|}
\hline \multicolumn{8}{|c|}{ Constant data } \\
\hline \multirow[t]{2}{*}{$\begin{array}{l}\text { Picking } \\
\text { speed }\end{array}$} & $\begin{array}{l}\text { Horizontal } \\
\text { Vx }\end{array}$ & $12 \mathrm{~m} / \mathrm{s}$ & \multirow[t]{4}{*}{$\begin{array}{c}\text { container } \\
\text { detail }\end{array}$} & Row & 10 & $\begin{array}{c}\text { container width } \\
\text { w }\end{array}$ & $0.5 \mathrm{~m}$ \\
\hline & $\begin{array}{l}\text { Vertical } \\
\text { Vy }\end{array}$ & $11 \mathrm{~m} / \mathrm{s}$ & & Column & 50 & $\begin{array}{c}\text { container length } \\
\text { b }\end{array}$ & $50 \mathrm{~m}$ \\
\hline $\begin{array}{c}\text { Goods } \\
\text { Volume }\end{array}$ & 1 & & & $\begin{array}{l}\text { Container } \\
\text { Quantity }\end{array}$ & 10 & & \\
\hline $\begin{array}{c}\text { Cart } \\
\text { Volume }\end{array}$ & 10 & & & $\begin{array}{l}\text { Container } \\
\text { Distance h }\end{array}$ & $1 \mathrm{~m}$ & & \\
\hline
\end{tabular}

Table 2. Random Generated Data of Goods

\begin{tabular}{|c|c|c|c|c|c|}
\hline \multicolumn{6}{|c|}{ Goods data (random generation) } \\
\hline ID & $\begin{array}{l}\text { Container } \\
\text { number }\end{array}$ & $\begin{array}{l}\text { Column } \\
\text { number }\end{array}$ & ID & $\begin{array}{l}\text { Container } \\
\text { number }\end{array}$ & $\begin{array}{l}\text { Column } \\
\text { number }\end{array}$ \\
\hline 1 & 7 & 27 & 16 & 8 & 42 \\
\hline 2 & 5 & 15 & 17 & 5 & 50 \\
\hline 3 & 3 & 39 & 18 & 9 & 12 \\
\hline 4 & 0 & 39 & 19 & 6 & 50 \\
\hline 5 & 8 & 36 & 20 & 2 & 27 \\
\hline 6 & 0 & 21 & 21 & 1 & 50 \\
\hline 7 & 8 & 40 & 22 & 6 & 1 \\
\hline 8 & 3 & 49 & 23 & 5 & 6 \\
\hline 9 & 8 & 3 & 24 & 1 & 40 \\
\hline 10 & 9 & 19 & 25 & 2 & 3 \\
\hline 11 & 5 & 39 & 26 & 2 & 20 \\
\hline 12 & 0 & 30 & 27 & 3 & 48 \\
\hline 13 & 4 & 15 & 28 & 9 & 21 \\
\hline 14 & 6 & 33 & 29 & 2 & 9 \\
\hline 15 & 2 & 14 & 30 & 1 & 33 \\
\hline
\end{tabular}

\subsection{Experimental Calculation and Analysis of Results}

Based on the above assumptions and simulation data, this paper calculates the results of optimization, sequence optimization and GA optimization, as shown in Table 3. The table lists the optimized picking paths and the elapsed time and required distance.

(1) calculation results before optimization

According to the calculation formula mentioned above, the time and distance of picking all of 30 pieces of random generated goods are respectively, time $=673 \mathrm{~s}$ and distance $=1216 \mathrm{~m}$

(2) Sequential optimization solution

The so-called sequential optimization is to divide the selected goods into three groups, and pick up the goods from the initial position $(0,1)$ in each group, which is similar to the method of picking goods in reality. The result of sequential optimization is: $\quad$ time $=448 \mathrm{~s}$, distance $=846 \mathrm{~m}$

(3) GA optimization solution

Process of GA algorithm to solve problem, as a candidate solution space to find proper solution to meet the requirement of problem or approximate solution of the search process, the GA algorithm to solve the optimization problem of calculating efficiency is higher, the applicable scope is quite wide. Based on the optimization strategy proposed in the last section, GA algorithm is used to optimize the solution. In GA solution, we set the population scale as 4 , the crossover rate is 0.99 , the variation rate is 0.01 , and the 
fitness function is $\mathrm{f}=1 /(0.08 \mathrm{t}+0.01 \mathrm{~d})$. Through GA solution, the solution of GA first-generation is: time $=345$, distance $=618$; The solution of the GA 5 th generation is: time $=293 \mathrm{~s}$, distance $=538 \mathrm{~m}$.

Table 3. Optimization of the Picking Process

\begin{tabular}{|c|c|c|c|c|c|c|c|c|}
\hline \multicolumn{3}{|c|}{ Sequential Optimization } & \multicolumn{3}{|c|}{$\begin{array}{l}\text { GA optimization } \\
\text { ( first generation) }\end{array}$} & \multicolumn{3}{|c|}{$\begin{array}{l}\text { GA optimization } \\
\text { ( } 5 \text { th generation) }\end{array}$} \\
\hline $\begin{array}{l}\text { First } \\
\text { trip }\end{array}$ & $\begin{array}{l}\text { Second } \\
\text { trip }\end{array}$ & $\begin{array}{l}\text { Third } \\
\text { trip }\end{array}$ & $\begin{array}{l}\text { First } \\
\text { trip }\end{array}$ & $\begin{array}{l}\text { Second } \\
\text { trip }\end{array}$ & Third trip & $\begin{array}{l}\text { First } \\
\text { trip }\end{array}$ & $\begin{array}{l}\text { Second } \\
\text { trip }\end{array}$ & $\begin{array}{l}\text { Third } \\
\text { trip }\end{array}$ \\
\hline 0 & 0 & 0 & 0 & 0 & 0 & 0 & 0 & 0 \\
\hline 6 & 12 & 30 & 25 & 6 & 21 & 25 & 6 & 4 \\
\hline 4 & 15 & 24 & 29 & 12 & 17 & 29 & 12 & 24 \\
\hline 3 & 20 & 21 & 13 & 30 & 4 & 13 & 30 & 21 \\
\hline 8 & 13 & 25 & 23 & 15 & 24 & 23 & 15 & 27 \\
\hline 2 & 11 & 29 & 2 & 26 & 5 & 2 & 26 & 8 \\
\hline 1 & 17 & 26 & 22 & 20 & 8 & 22 & 20 & 17 \\
\hline 9 & 14 & 27 & 9 & 3 & 19 & 9 & 3 & 19 \\
\hline 5 & 19 & 23 & 18 & 11 & 16 & 18 & 11 & 5 \\
\hline 7 & 16 & 22 & 10 & 14 & 7 & 10 & 14 & 7 \\
\hline 10 & 18 & 28 & 28 & 1 & 27 & 28 & 1 & 16 \\
\hline 0 & 0 & 0 & 0 & 0 & 0 & 0 & 0 & 0 \\
\hline \multicolumn{3}{|c|}{ Time $\mathrm{t}=448$,distance $\mathrm{d}=846$} & \multicolumn{3}{|c|}{ Time $t=345$, distance $d=618$} & \multicolumn{3}{|c|}{ Time $t=293$, distance $d=538$} \\
\hline
\end{tabular}

According to the above calculation results, the optimization results shown in Fig. 2 are obtained. According to the Fig. 2, the optimized time and distance have been greatly reduced, which greatly improved the efficiency.

The simulation experiment of this section shows that there is still a lot of optimization space in the present picking strategy, and the optimization strategy proposed in this paper can have obvious optimization effect.

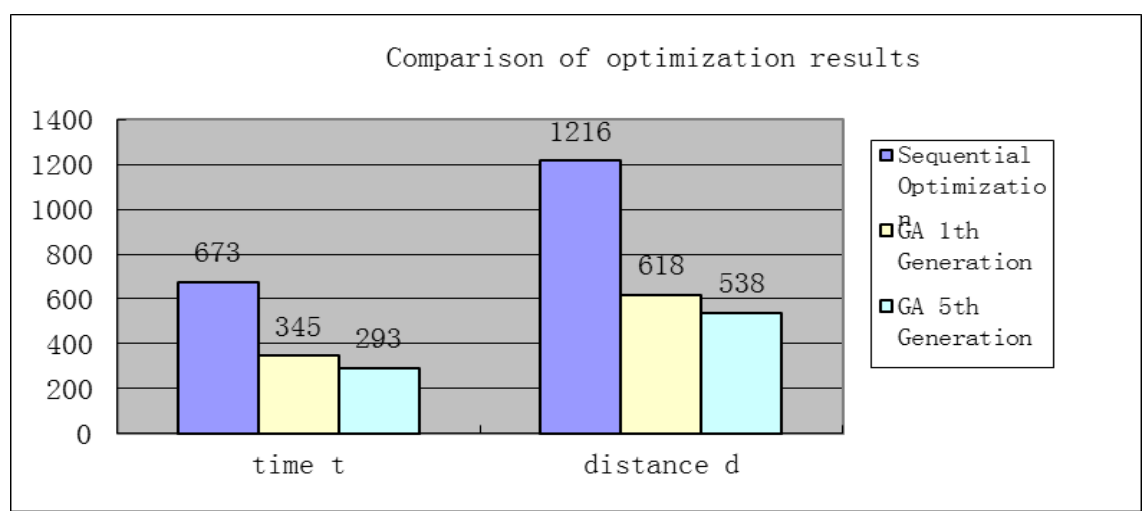

Fig. 2. Comparison of optimization results.

\section{Conclusion}

The advantage of GA genetic algorithm is that it can carry out multi-point search in the solution space when using probabilistic search technology, which can avoid falling into the local minimum value, increase the flexibility of search, and improve the computing speed of the system. This research uses genetic algorithm to solve the optimization problem of the warehousing business of State Grid, which is very 
important to improve the efficiency of material distribution of State Grid. In this paper, taking the sorting business as an example, a sorting service optimization strategy based on GA algorithm is proposed. The simulation results show that the optimization of GA algorithm reduces the picking time and distance compared with the sequential optimization and pre-optimization, improves the efficiency of picking, and proves the reliability of the optimization strategy. The optimization strategy of the sorting service will also have a positive reference to the optimization of other warehousing services, such as the warehousing, the upper and lower shelves, etc.

\section{Acknowledgment}

This paper is supported by The Key Project of Ministry of Education of National Education Science (DAC150242)

\section{References}

[1] Huaixiang, L. (2011). Practice of Warehouse Management. Beijing: Peking University Press.

[2] Jianwei, S. (2015). A brief analysis of optimization management of material storage in power enterprises. Research on Urban Construction Theory, 2015(10), 54-60.

[3] Qiankun, L. (2014). Optimization of warehousing and distribution management of He Bei branch of state grid. Modern Trading Industry, 26(7), 168-178.

[4] Guoliang, C. (2001). Mechanical Application of Genetic Algorithms. Beijing: People's Post and Telecommunications Press.

[5] Xin, J., Yian, P., \& Jing, W. (2014). Optimization of the financial product marketing forecast based on GA-Bp neural network. Journal of Communication, 2014(Z2), 20-25.

[6] Chen, S., \& Chengyi, L. (2012). Prediction of clothing sales based on genetic algorithm and BP neural network. Operation and Management, 2012(2), 48-52.

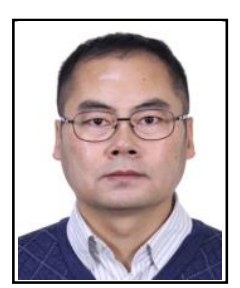

Xin Jin was born in Inner Mongolia of China in 1974. He received the Ph.D degree in control theory and engineering from DongHua University China in 2004. He is a professor at Central University of Finance and Economics. His research interests include big data analysis and business intelligent, etc. 